\title{
Insulin response to glucose and glucose tolerance following feeding in sheep
}

\author{
BY Y. SASAKI, H. TAKAHASHI, H. ASO, K. HIKOSAKA, \\ A. HAGINO AND S. ODA \\ Laboratory of Animal Physiology, Tohoku University, Amamiya, Sendai 980, Japan
}

(Received 14 February 1984-Accepted 4 April 1984)

1. Sheep offered a roughage diet for $4 \mathrm{~h}$ daily were injected intravenously with glucose before and at various times after feeding. The insulin secretory response to glucose and the rate of disappearance of injected glucose were determined.

2. While the basal concentration of plasma insulin was unchanged, the base-line plasma glucose concentration tended to decrease during the meal.

3. The glucose load brought about an increase in the plasma insulin concentration at each injection, but the insulin response to glucose and the rate of glucose disposal were increased during the meal.

4. On varying the time of feeding between 08.00 and 16.00 hours, the increase in the insulin response to glucose and in the rate of glucose disposal always appeared to be related to the giving of food, independent of the time food was offered.

5. It is concluded that feeding increases the insulin response to an intravenous glucose load even when the increase in the basal level of plasma insulin on feeding is very modest in sheep given a roughage diet. The increased insulin response and glucose disposal rate following feeding did not appear to be related to diurnal rhythms in insulin secretory activity or glucose metabolism.

It has been reported that the plasma insulin concentration is increased after feeding in ruminant animals (Bassett, 1974b; Hart et al. 1975; Chase et al. 1977; Thompson et al. 1978; de Jong, 1981; Barry et al. 1982), as in other mammalian species, reflecting an augmented release of insulin by the pancreas. Insulin is known to be at the centre of metabolic regulation in ruminants, as in other species (Bassett, 1975). Insulin stimulates the uptake and incorporation of amino acids into protein, inhibits proteolysis, stimulates lipogenesis and inhibits lipolysis. The increase in plasma insulin concentration after feeding may be an expression of the shift of metabolism from a catabolic towards an anabolic state at this stage. An increased activity of the endocrine pancreas of ruminants in response to feeding has mainly been demonstrated in terms of increased plasma hormone concentrations. It has, however, been reported that plasma insulin levels are not so clearly increased in response to feeding when animals are fed on a roughage diet compared with animals fed on concentrate diets (Trenkle, 1970; Lofgren \& Warner, 1972; Ross \& Kitts, 1973; Jenny \& Polan, 1975).

In the present study we have therefore measured the changes following feeding in the insulin secretory response to an intravenous glucose load and in the rate of removal of the injected glucose from the plasma. This procedure was used to determine the effect of feeding on the insulin response to a fixed stimulus and on the ability of the tissues to utilize glucose in sheep fed on a roughage diet.

\section{MATERIALS AND METHODS}

Animals and diets

Fifteen cross-bred sheep aged 3-7 years and weighing 37-50 kg were used. The sheep were housed in metabolism cages in an experimental room at an air temperature of $18-20^{\circ}$. Animals were shorn bimonthly to provide comfortable insulation, and to keep this variable 
reasonably constant. They had their left common carotid artery chronically placed in a loop of skin, under anaesthesia induced by sodium pentobarbitone, at least 2 months before experiments began. During the postoperative period the animals were trained to become accustomed to the experimental procedure and surroundings. Catheters were inserted into the jugular vein through a hypodermic needle at least 1 week before the experiments began. The catheters were flushed and filled with a sterile solution of trisodium citrate dihydrate $(38 \mathrm{~g} / 1)$. They were offered orchard-grass (Dactylis glomerata) hay once daily with food available for $4 \mathrm{~h}$. The amount of food consumed was measured on days when experiments were performed. The daily food intake (mean with SE) ranged from $59.2(1 \cdot 1)$ to $67.6(0 \cdot 7) \mathrm{g}$ dry matter $(\mathrm{DM}) / \mathrm{kg}$ body-weight ${ }^{0.75}$ for the sheep with minimum and maximum bodyweights respectively. The mean (with SE) daily food intake for the fifteen sheep used was $62.9(1.4) \mathrm{g} \mathrm{DM} / \mathrm{kg}$ body-weight ${ }^{0.75}$. The animals were used to laboratory personnel entering the experimental room at various times of day and working on them while they were not being fed.

\section{Glucose injection}

Expt 1 . Ten sheep were offered hay once daily at 12.00 hours with feed remaining available over a period between 12.00 and 16.00 hours. For a dose of $0.625 \mathrm{mmol}$ glucose $/ \mathrm{kg}$ body-weight to be administered, they were given a varying volume of $2.5 \mathrm{M}$-glucose solution which was injected intravenously through the catheter during $1 \mathrm{~min}$, with one injection/d at $10.00,12.30,14.30,18.00,23.00$ or 04.00 hours. The injection of glucose for each sheep was performed at different times every $3 \mathrm{~d}$, since the insulin secretory response of sheep to intravenous glucose is unchanged when injections are repeated at this frequency (Sasaki \& Takahashi, 1980).

Expt 2. Five sheep were offered hay at 08.00 hours with feed available for $4 \mathrm{~h}$ between 08.00 and 12.00 hours. They had the same dose of glucose administered, as in Expt 1 at $06.00,08.30,10.30$ and 14.00 hours. After the experiments using the 08.00 hours feeding regimen, the time of feeding for these five sheep was changed to 16.00 hours with feed again available for $4 \mathrm{~h}$, between 16.00 and 20.00 hours. In a period of 1 week the animals adapted to the new feeding time. Glucose injection was done at 14.00, 16.30, 18.30 and 22.00 hours on subsequent days when they were fed at 16.00 hours. The two groups of animals used for Expts 1 and 2 were separated to prevent disturbance when they were offered diets at different times of day.

\section{Blood sampling}

The exteriorized carotid artery was catheterized after puncturing at least $1 \mathrm{~h}$ before the injection of glucose. When glucose injection was performed during a meal, carotid catheterization was done at least $1 \mathrm{~h}$ before feeding. Two base-line samples, $15 \mathrm{~min}$ apart, were obtained before the injection of glucose and samples were taken at $5,10,15,30,45$, 60 and $90 \mathrm{~min}$ after injection. The mean of the two base-line values was taken as the value at zero time.

\section{Analyses}

Arterial blood collected into heparinized syringes was immediately transferred into polyethylene test-tubes cooled in ice-cold water and centrifuged at $8000 \mathrm{~g}$ at $4^{\circ}$. Plasma was deproteinized with $0.3 \mathrm{M}$-trichloroacetic acid and the supernatant fraction stored at $-20^{\circ}$ until glucose was determined by the glucose oxidase (EC 1.1.3.4) method of Huggett \& Nixon (1957). A sample of plasma was stored at $-20^{\circ}$ for insulin assay (Sasaki \& Takahashi, 1980). 
Table 1. Plasma insulin and glucose concentrations at various times of day in sheep offered orchard-grass (Dactylis glomerata) hay between 12.00 and 16.00 hours

(The significance of difference between the times of day was determined using Duncan's test. Mean values for ten sheep. Values in parentheses represent mean $\log _{10}$ of insulin concentrations with their standard errors)

\begin{tabular}{|c|c|c|c|c|c|}
\hline \multirow{2}{*}{$\begin{array}{l}\text { Time of } \\
\text { day } \\
\text { (hours) }\end{array}$} & \multicolumn{3}{|c|}{$\begin{array}{l}\text { Plasma insulin } \\
(\mathrm{mU} / \mathrm{l})\end{array}$} & \multicolumn{2}{|c|}{$\begin{array}{c}\text { Plasma glucose } \\
(\mathrm{g} / 1)\end{array}$} \\
\hline & Mean & (Mean $\log _{10}$ ) & (SE) & Mean & SE \\
\hline 10.00 & $6 \cdot 2$ & $\left(0.79^{\mathrm{a}}\right)$ & $(0 \cdot 13)$ & $0 \cdot 604^{\mathrm{ab}}$ & 0.029 \\
\hline 12.30 & $10 \cdot \overline{2}$ & $\left(1 \cdot 01^{a}\right)$ & $(0 \cdot 10)$ & $0.577^{a}$ & 0.014 \\
\hline 14.30 & $12 \cdot 6$ & $\left(1 \cdot 10^{\mathrm{a}}\right)$ & $(0 \cdot 12)$ & $0.563^{\mathrm{a}}$ & $0 \cdot 013$ \\
\hline 18.00 & $6 \cdot 2$ & $\left(0 \cdot 79^{a}\right)$ & $(0.16)$ & $0.623^{a b c}$ & 0.022 \\
\hline 23.00 & $8 \cdot 9$ & $\left(0.95^{\mathrm{u}}\right)$ & $(0.12)$ & $0.678^{\mathrm{c}}$ & 0.018 \\
\hline 04.00 & $7 \cdot 2$ & $\left(0 \cdot 86^{\mathrm{a}}\right)$ & $(0 \cdot 17)$ & $0662^{b c}$ & 0.013 \\
\hline
\end{tabular}

a,b,c Mean values in the same vertical column not sharing common superscript letters differed significantly $(P<0.05)$.

\section{Calculations and statistics}

The insulin areas under the insulin concentration curves above zero levels were calculated between 0 and $60 \mathrm{~min}$ after injection and were expressed as $\mathrm{mU} / \mathrm{min}$ per 1 . Glucose disappearance rates $(K)$ were calculated using the equation:

$$
\ln C_{t}=\ln C_{0}-K \times t
$$

using the incremental plasma glucose values $(\mathrm{g} / 1)$ above the base-line values between 10 and $30 \mathrm{~min}$ after glucose injection. In this equation, $C_{t}$ is the increment of the plasma glucose concentration at time $t(\mathrm{~min}), C_{0}$ is the increment in plasma glucose concentration at $t=0$ and $K$ is the disappearance rate of injected glucose from plasma.

In Expts 1 and 2, one-way analyses of variance were carried out to test the influence of the times. The significance of differences in basal levels of plasma insulin and glucose between the times in Expt 1 were tested by Duncan's test. The significance of differences in insulin areas, and glucose disappearance rates, between the times within each feeding regimen were also determined using Duncan's test. The absolute concentrations of insulin are not normally distributed but their logarithms often are (Bassett \& Thorburn, 1971); therefore concentrations of insulin were converted to logarithms for statistical analysis. The insulin areas calculated using the absolute insulin concentrations were also transformed to logarithms for statistical analysis. Antilogs of mean values are given for ease of interpretation.

\section{RESULTS}

\section{Expt 1}

Basal concentration. There was no significant difference in the base-line concentration of plasma insulin between the times of day in sheep fed on hay at 12.00 hours (Table 1). The difference in basal concentrations of plasma glucose between the times of day was statistically significant, with a low concentration during the meal compared with the values 11-16 $\mathrm{h}$ after feeding.

Insulin response to glucose. The effects of intravenous injection of glucose at different times of day on plasma insulin concentrations in sheep fed at 12.00 hours are shown in Fig. 1 . 


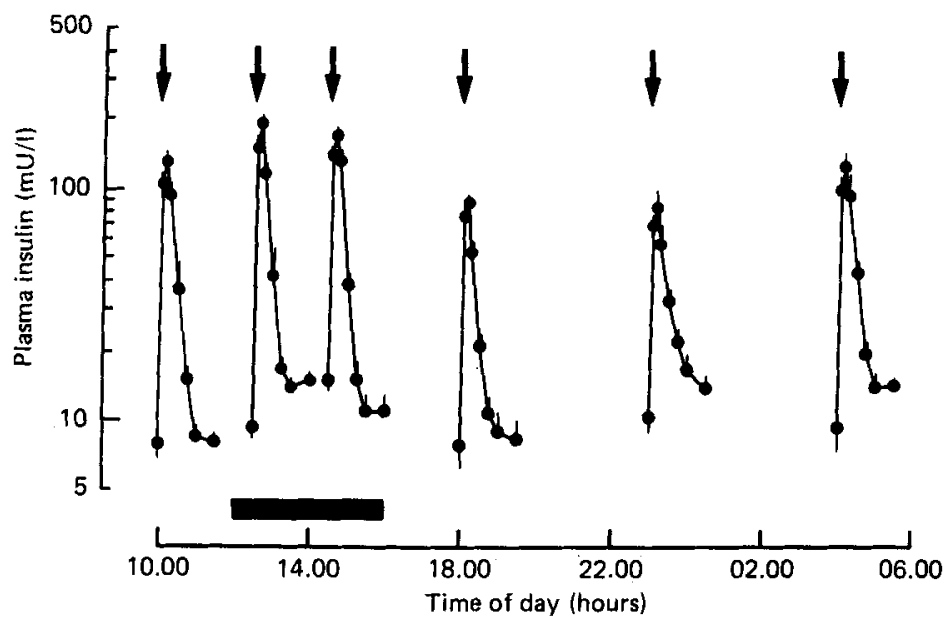

Fig. 1. Plasma insulin concentrations in sheep given a glucose load before and at various times after feeding. Animals were offered orchard-grass (Dactylis glomerata) hay between 12.00 and 16.00 hours ( $)$. On any $1 \mathrm{~d}$ a single intravenous injection of glucose $(0.625 \mathrm{mmol} / \mathrm{kg}$ body-weight $)$ was given over $1 \mathrm{~min}(\downarrow)$ ) at either $10.00,12.30,14.30,18.00,23.00$ or 04.00 hours. Injections were repeated at different times every $3 \mathrm{~d}$. Mean values for ten sheep with their standard errors represented by vertical bars.

Table 2. Insulin response to glucose and disappearance rate of glucose at various times of day in sheep offered orchard-grass (Dactylis glomerata) hay between 12.00 and 16.00 hours

(Insulin area, expressed as $\mathrm{mU} / \mathrm{min}$ per 1 , is the area under the insulin concentration curve above zero level between 0 and $60 \mathrm{~min}$ following intravenous glucose injection at a dose of $0.625 \mathrm{mmol} / \mathrm{kg}$ body-weight. Values in parentheses represent mean $\log _{10}$ of insulin areas with their standard errors. Glucose disappearance rate expressed as $K$ was calculated using the equation: $\ln C_{t}=\ln C_{0}-K \times t$ using the incremental plasma glucose values $(\mathrm{g} / \mathrm{l})$ above the base-line levels between 10 and 30 min after glucose injection. $C_{t}$ is the increment of the plasma glucose concentration at time $t(\mathrm{~min}), C_{0}$ is the increment in plasma glucose concentration at $t=0$ and $K$ is the disappearance rate of injected glucose from plasma. Mean values for ten sheep. The significance of difference between the times was determined using Duncan's test)

\begin{tabular}{|c|c|c|c|c|c|}
\hline \multirow{2}{*}{$\begin{array}{c}\text { Time of } \\
\text { day } \\
\text { (hours) }\end{array}$} & \multicolumn{3}{|c|}{$\begin{array}{c}\text { Insulin area } \\
(\mathrm{mU} / \mathrm{min} \text { per } \mathrm{l})\end{array}$} & \multicolumn{2}{|c|}{$\begin{array}{c}K \\
\left(\times 10^{-2}\right)\end{array}$} \\
\hline & Mean & (Mean $\log _{10}$ ) & (SE) & Mean & $\mathbf{S E}$ \\
\hline 10.00 & $45 \cdot 7$ & $\left(1 \cdot 66^{b c}\right)$ & $(0.05)$ & $5 \cdot 50^{\mathrm{b}}$ & 0.82 \\
\hline 12.30 & $66 \cdot 1$ & $\left(1.82^{a}\right)$ & $(0.04)$ & $13 \cdot 58^{\mathrm{a}}$ & $2 \cdot 63$ \\
\hline 14.30 & $60 \cdot 3$ & $\left(1 \cdot 78^{a b}\right)$ & $(0.04)$ & $8 \cdot 56^{a b}$ & 1.41 \\
\hline 18.00 & 30.9 & $\left(1 \cdot 49^{d}\right)$ & $(0.05)$ & $5 \cdot 57^{b}$ & 1.49 \\
\hline 23.00 & $36 \cdot 3$ & $\left(1 \cdot 56^{\mathrm{cd}}\right)^{\prime}$ & $(0.05)$ & $3 \cdot 58^{b}$ & 0.40 \\
\hline 04.00 & $49 \cdot 0$ & $\left(1 \cdot 69^{a b c}\right)$ & $(0.06)$ & $7 \cdot 01^{b}$ & 3.00 \\
\hline
\end{tabular}

$a, b, c, d$ Mean values in the same vertical column not sharing common superscript letters differed significantly $(P<0 \cdot 05)$.

Glucose injection brought about an abrupt increase in the plasma insulin concentration, reaching a peak $10 \mathrm{~min}$ after each injection of glucose but, during the meal, the peak plasma insulin concentration was increased. Thus, there were significant differences in the insulin areas between the times of day (Table 2), with a increased insulin response to glucose apparent during the meal. 


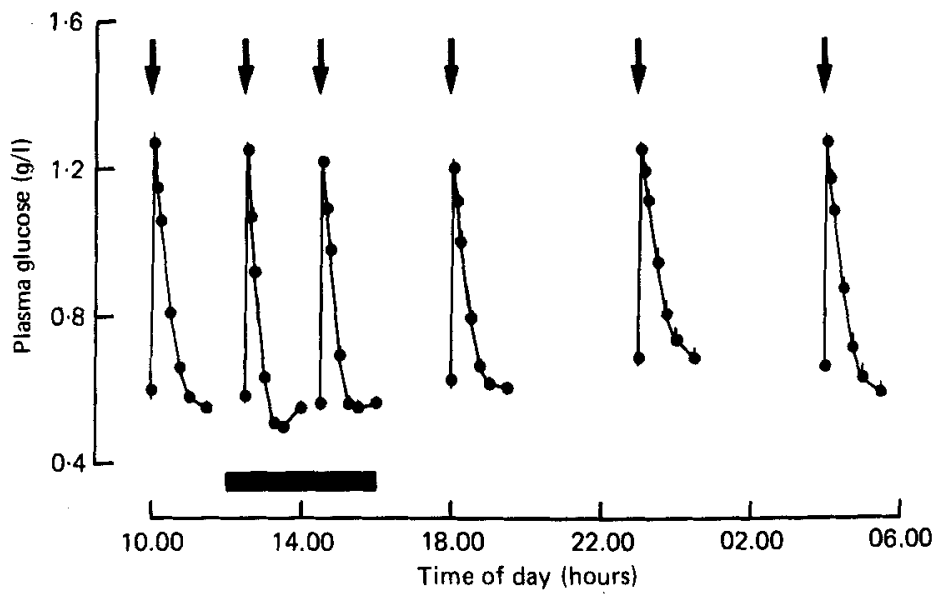

Fig. 2. Plasma glucose concentrations in sheep given a glucose load before and at various times after feeding. Animals were offered orchard-grass (Dactylis glomerata) hay between 12.00 and 16.00 hours (D). On any $1 \mathrm{~d}$ a single intravenous injection of glucose $(0.625 \mathrm{mmol} / \mathrm{kg}$ body-weight $)$ was given over $1 \cdot \min (\downarrow)$ at either $10.00,12.30,14.30,18.00,23.00$ or 04.00 hours. Injections were repeated at different times every $3 \mathrm{~d}$. Mean values for ten sheep with their standard errors represented by vertical bars.

Table 3. Effect of varying the time of feeding on insulin response to glucose and rate of glucose disappearance in sheep

(Five sheep received intravenous glucose injections at a dose of $0.625 \mathrm{mmol} / \mathrm{kg}$ before and at various times after feeding on days when they were offered orchard-grass (Dactylis glomerata) hay either between 08.00 and 12.00 hours or between 16.00 and 20.00 hours. Calculations for insulin area and disappearance rate of injected glucose from plasma $(K)$ are as for Table 2 . Values in parentheses represent mean $\log _{10}$ of insulin areas with their standard errors. Mean values for five sheep. The significance of difference between the times within each feeding regimen was determined using Duncan's test)

\begin{tabular}{|c|c|c|c|c|c|c|}
\hline \multirow{2}{*}{$\begin{array}{l}\text { Time of } \\
\text { feeding } \\
\text { (hours) }\end{array}$} & \multirow{2}{*}{$\begin{array}{l}\text { Time of } \\
\text { day of } \\
\text { glucose } \\
\text { injection } \\
\text { (hours) }\end{array}$} & \multicolumn{3}{|c|}{$\begin{array}{c}\text { Insulin area } \\
(\mathrm{mU} / \mathrm{min} \text { per } 1)\end{array}$} & \multicolumn{2}{|c|}{$\begin{array}{c}K \\
\left(\times 10^{-2}\right)\end{array}$} \\
\hline & & Mean & $\left(\right.$ Mean $\left.\log _{10}\right)$ & (SE) & Mean & $\mathrm{SE}$ \\
\hline 08.00 & $\begin{array}{l}06.00 \\
08.30 \\
10.30 \\
14.00\end{array}$ & $\begin{array}{l}23 \cdot 4 \\
36 \cdot 3 \\
36 \cdot 3 \\
27 \cdot 5\end{array}$ & $\begin{array}{l}\left(1.37^{\mathrm{a}}\right) \\
\left(1.56^{\mathrm{a}}\right) \\
\left(1.56^{\mathrm{a}}\right) \\
\left(1.44^{\mathrm{a}}\right)\end{array}$ & $\begin{array}{l}(0 \cdot 14) \\
(0 \cdot 14) \\
(0 \cdot 12) \\
(0.13)\end{array}$ & $\begin{array}{r}4.29^{\mathrm{c}} \\
11.79^{\mathrm{a}} \\
9.17^{\mathrm{b}} \\
3.85^{\mathrm{c}}\end{array}$ & $\begin{array}{l}0.98 \\
5 \cdot 31 \\
1 \cdot 59 \\
0.34\end{array}$ \\
\hline 16.00 & $\begin{array}{l}14.00 \\
16.30 \\
18.30 \\
22.00\end{array}$ & $\begin{array}{l}22 \cdot 9 \\
36 \cdot 3 \\
32 \cdot 4 \\
24 \cdot 0\end{array}$ & $\begin{array}{l}\left(1 \cdot 36^{\mathrm{a}}\right) \\
\left(1 \cdot 56^{\mathrm{a}}\right) \\
\left(1 \cdot 51^{\mathrm{a}}\right) \\
\left(1 \cdot 38^{\mathrm{a}}\right)\end{array}$ & $\begin{array}{l}0.13) \\
(0.13) \\
(0.14) \\
(0.13)\end{array}$ & $\begin{array}{r}4 \cdot 07^{\mathrm{b}} \\
12 \cdot 33^{\mathrm{a}} \\
12 \cdot 65^{\mathrm{a}} \\
3 \cdot 50^{\mathrm{b}}\end{array}$ & $\begin{array}{l}0.46 \\
5.40 \\
5 \cdot 24 \\
0.24\end{array}$ \\
\hline
\end{tabular}

$a, b, c$ Mean values in the same vertical column not sharing common superscript letters differed significantly $(P<0.05)$.

Glucose disappearance rate. The changes in the plasma glucose concentration following the injection of glucose at each time of day are shown in Fig. 2. The peak plasma concentrations $5 \mathrm{~min}$ after the injection of glucose (mean with SE) ranged from 1.204 $(0.028)$ to $1.267(0.020) \mathrm{g} / \mathrm{l}$, reflecting the similar extent of hyperglycaemia induced by gluocse injection at each time of day. There were, however, significant differences in the 
glucose disappearance rate, expressed as $K$, between the times of day (Table 2). Much higher rates of the glucose disappearance were observed during the meal.

\section{Expt 2}

The effect of varying the time of feeding on the insulin response to glucose and the glucose disappearance rate is shown in Table 3. The glucose disappearance rate was significantly increased with a trend of increases in the insulin response area during the meal in sheep offered the hay diet between 08.00 and 12.00 hours, but due to variation between animals the trend failed to reach statistical significance. A similar increase in the glucose disappearance rate was apparent when animals were offered the hay diet between 16.00 and 20.00 hours. The insulin responses to glucose in these animals were somewhat lower than in the group of sheep used for Expt 1.

\section{DISCUSSION}

The results of the present study indicate that the effect of feeding in stimulating the secretion of insulin in reponse to an intravenous glucose load can be demonstrated, even when the increase in the basal level of plasma insulin is very modest in sheep given a roughage diet. Although the blood glucose concentration is usually considered to be the principal metabolic substrate regulating insulin release by the beta cells of most animal species, the plasma glucose concentration itself may not be a major determinant of insulin secretion in sheep under physiological conditions (Bassett 1975). Other metabolites, such as volatile fatty acids, have been suggested to be effective stimulants of insulin secretion in ruminant animals (Horino et al. 1968; Sasaki et al. 1977; Sasaki \& Takahashi, 1983) in which volatile fatty acids are produced as end-products of rumen fermentation. It seems valid, however, to use glucose as an exogenous stimulant for insulin release in sheep in order to evaluate simultaneously the activity of the insulin secretion process and the rate of glucose metabolism, since glucose has been shown to be a direct stimulant for insulin release by perifused fragments of sheep pancreas (Sasaki et al. 1977).

It has been reported that insulin secretion in ruminants is markedly stimulated by feeding, the increase being greater with high-concentrate than with high-roughage diets (Trenkle, 1970; Lofgren \& Warner, 1972; Ross \& Kitts, 1973; Bhattacharya \& Alulu, 1975). Although it is still unclear whether the difference between these diets is simply a function of the digestible nutrient intake or if it reflects differences in the rate of fermentation and proportions of the individual volatile fatty acids produced in the rumen (Bassett, 1978), the insulinotropic actions of volatile fatty acids (Manns \& Boda, 1967; Bassett, 1972; Weekes, 1975; Brockman, 1978), protein in the intestine (Bassett et al. 1971) and reflex vagal activation (Bassett, 1974a) may be able to augment the insulin secretory response to an intravenous glucose load more effectively following feeding than before feeding.

Very little glucose is absorbed from the small intestine in adult ruminants fed on roughage diets, the majority of basal glucose flux being provided by hepatic gluconeogenesis, which is usually greatest during the feeding period. When exogenous glucose is administered, the rate of glucose disposal may relate to alterations in peripheral glucose utilization as well as to changes in the rate of hepatic glucose output. With regard to the former, the increased rate of glucose disappearance during the meal appears to be due in part to the increase in the peripheral utilization of glucose mediated through the augmented secretion of insulin in response to the administered glucose, though a recent study has shown that the responsiveness of peripheral glucose utilization to insulin is relatively low in adult sheep (Weekes et al. 1983). The action of insulin to increase the rate of glucose disposal via suppression of hepatic glucose output and stimulation of hepatic glucose uptake seems 
probably to be a minor route of glucose disposal in sheep, since the suppression of hepatic glucose production by insulin has been reported to be relatively insensitive in this species (Weekes et al. 1983). The suppression of glucagon secretion by hyperglycaemia induced by the intravenous glucose load, as reported in simple-stomach species (Bloom, 1981), could increase the rate of glucose disposal via a reduced glucose output from the liver. Previous work from this laboratory has, however, demonstrated that a primed continuous glucose infusion to sustain a plasma glucose concentration around $1.5 \mathrm{~g} / 1$ for $1 \mathrm{~h}$ did not induce a significant decrease in plasma glucagon in sheep (Sasaki et al. 1982). We are not able to explain the relatively-weak insulin secretion $6 \mathrm{~h}$ after feeding (Table 2), while the glucose disposal was retarded $11 \mathrm{~h}$ after feeding. Since glucose disposal is normally considered as being dependent on the amount of insulin secreted, the results we obtained are particularly striking.

Other hormones which affect glucose metabolism may have influenced the response to feeding which we found. Plasma catecholamine levels have not been measured. It seems unlikely that cortisol could be involved in an increased glucose disappearance following feeding, since plasma cortisol levels in sheep did not appear to be influenced by food ingestion or by the diet consumed (Bassett, 1974b). The plasma levels of thyroid hormones also appear to be unaffected by feeding in growing lambs (Barry et al. 1982). However, the possibility that the greater glucose disappearance after feeding than before feeding is at least partly mediated through changes in plasma growth hormone, which has inhibitory effects on glucose metabolism and antagonizes insulin action in ruminants (Bassett, 1975), cannot be excluded. Growth hormone has been reported to decrease in response to feeding in sheep (Wallace \& Bassett, 1970; Bassett, 1972; Bassett, 1974a, b).

On varying the time of feeding, the increase in the insulin response to the exogenous glucose load, as well as in the glucose disappearance rate, always appeared to be related to the giving of food, independent of the time it was offered, although the trend of the increases in the insulin response failed to reach statistical significance in Expt 2. Thus it seems possible that the increases in insulin secretion and in the rate of disappearance of injected glucose from the blood could be brought about by feeding. However, further detailed study of the diurnal rhythms in either insulin secretory activity or in the metabolism of glucose is required.

The authors are indebted to Drs A. Ohneda and T. Fujishima, Tohoku University School of Medicine, Sendai, Japan, for their generosity in affording excellent facilities for the insulin assay. The authors are most grateful for the comments on the manuscript of Dr T. E. C. Weekes, University of Newcastle. This work was in part supported by a Grantin-Aid for Scientific Research from The Japanese Education Ministry.

\section{REFERENCES}

Barry, T. N., Manley, T. R., Redekopp, C., Davis, S. R., Fairclough, R. J. \& Lapwood, K. R. (1982). British Journal of Nutrition 47, 319-329.

Bassett, J. M. (1972). Australian Journal of Biological Science 25, 1277-1287.

Bassett, J. M. (1974a). Australian Journal of Biological Science 27, 157-166.

Bassett, J. M. (1974b). Australian Journal of Biological Science 27, 167-181.

Bassett, J. M. (1975). In Digestion and Metabolism in the Ruminant, pp. 383-398 [I. W. McDonald and

A. C. I. Warner, editors]. Armidale: University of New England Publishing Unit.

Bassett, J. M. (1978). Proceedings of the Nutrition Society 37, 273-280.

Bassett, J. M. \& Thorburn, G. D. (1971). Journal of Endocrinology 50, 59-74.

Bassett, J. M., Weston, R. H. \& Hogan, J. P. (1971). Australian Journal of Biological Science 24, 321-330.

Bhattacharya, A. N. \& Alulu, M. (1975). Journal of Animal Science 41, 225-233.

Bloom, S. R. (1981). In Glucagon, pp. 99-113 [R. H. Unger and L. Orci, editors]. New York: Elsevier.

Brockman, R. P. (1978). Canadian Verterinary Journal 19, 55-62. 
Chase, L. E., Wangsness, P. J., Kavanaugh, J. F., Griel, L. C. Jr. \& Gahagan, J. H. (1977). Journal of Dairy Science 60, 403-409.

de Jong, A. (1981). Journal of Agricultural Science, Cambridge 96, 659-668.

Hart, I. C., Bines, J. A., Balch, C. C. \& Cowie, A. T. (1975). Life Science 16, 1285-1292.

Horino, M., Machlin, M. J., Hertelendy, F. \& Kipnis, D. M. (1968). Endocrinology 83, 118-128.

Huggett, A. G. \& Nixon, D. A. (1957). Biochemical Journal 66, 12.

Jenny, B. F. \& Polan, C. E. (1975). Journal of Dairy Science 58, 512-514.

Lofgren, P. A. \& Warner, R. G. (1972). Journal of Animal Science 35, 1239-1247.

Manns, J. G. \& Boda, J. M. (1967). American Journal of Physiology 212, 747-755.

Ross, J, P. \& Kitts, W. D. (1973). Journal of Nutrition 103, 488-493.

Sasaki, Y. \& Takahashi, H. (1980). Journal of Physiology, London 306, 323-335.

Sasaki, Y. \& Takahashi, H. (1983). Journal of Physiology, London 334, 155-167.

Sasaki, Y., Takahashi, H., Aso, A., Ohneda, A. \& Weekes, T. E. C. (1982). Endocrinology 111, 2070-2076.

Sasaki, Y., Weekes, T. E. C. \& Bruce, J. B. (1977). Journal of Endocrinology 72, 415-416.

Thompson, G. E., Bassett, J. M. \& Bell, A. W. (1978). British Journal of Nutrition 39, 219-226.

Trenkle, A. (1970). Journal of Nutrition 100, 1323-1330.

Wallace, A. L. C. \& Bassett, J. M. (1970). Journal of Endocrinology 47, 21-36.

Weekes, T. E. C. (1975). Journal of Physiology, London 254, 80-81.

Weekes, T. E. C., Sasaki, Y. \& Tsuda, T. (1983). American Journal of Physiology 244, E335-E345. 